\title{
CARACTERIZAÇÃO FÍSICO-QUÍMICA E MICROBIOLÓGICA QUANTO A INFLUÊNCIA DE RESÍDUOS NA QUALIDADE DA ÁGUA DO RIO TOCANTINS, MARGEM ESQUERDA (MARABÁ - PA)
}

\section{ARTIGO ORIGINAL}

BITENCOURT, Emanoelen Bitencourt $\mathrm{e}^{1}$

ALMEIDA, Karina Miranda de ${ }^{2}$

SANTOS, Luana Mariza Morais dos ${ }^{3}$

JÚNIOR, Antônio Pereira ${ }^{4}$

BITENCOURT, Emanoelen Bitencourt e. Et al. Caracterização físico-química e microbiológica quanto a influência de resíduos na qualidade da água do Rio Tocantins, margem esquerda (MARABÁ - PA). Revista Científica Multidisciplinar Núcleo do Conhecimento. Ano 04, Ed. 06, Vol. 11, pp. 05-26. Junho de 2019. ISSN: 2448-0959

\section{RESUMO}

A água é vital para a continuidade da vida no planeta, mas a qualidade dos corpos hídricos é alterada pelo descarte inadequado de materiais orgânicos secos e úmidos, em especial em ambiente urbano, ainda que haja parâmetros e normas voltadas para esta problemática. O objetivo dessa pesquisa foi a caracterização da água do rio Tocantins, em Marabá - PA, quanto aos padrões hídricos físico-químicos e microbiológicos, em dois pontos sob a influência da disposição de resíduos, no

\footnotetext{
${ }^{1}$ Graduanda em Engenharia Ambiental.

2 Graduanda em Engenharia Ambiental.

${ }^{3}$ Graduanda em Engenharia Ambiental.

${ }^{4}$ Mestre em Ciências Ambientais.
} 
período seco e chuvoso, e relacionar os dados obtidos com as normas legais. $\mathrm{O}$ método empregado foi o dedutivo, a abrangência da pesquisa foi quantitativa e qualitativa e o procedimento foi experimental, executado a partir do uso do Manual da FUNASA, Norma da SABESP, Método de Winkler e SMWW, com associação ao levantamento de dados documentais, cujo recorte temporal situou-se entre 2010 e 2018. Os dados obtidos indicaram que os parâmetros hídricos físicos estão em concordância ao estabelecido para águas doces Classe 2, Resolução CONAMA n. 357/2005, e em desacordo quanto aos critérios hídricos químicos. Já os dados dos padrões de balneabilidade indicaram água imprópria para a recreação de contato primário, pois, há despejo de remanescentes residuais, contendo substâncias como óleos e graxas, que são passíveis de causar riscos à saúde ou comprometer a recreação, de acordo com a Resolução n. 274:2000. Portanto, o trecho analisado do rio está em desconformidade tanto na classificação de águas doces quanto na balneabilidade.

palavras-chave: balneabilidade, classificação das águas doces, parâmetros hídricos de qualidade.

\section{INTRODUÇÃO}

A água é um recurso natural essencial à vida na Terra. Em contrapartida, a maneira de utilização desse recurso, ocorre, diversas vezes, de forma indevida, o que leva a não manutenção da qualidade, menor disponibilidade e alteração das características naturais do afluente, que também possui solução gasosa e sólida. Somado a poluição natural, o gerenciamento impróprio de áreas, a falta de tratamento de esgoto e o descarte indiscriminado de resíduos são fatores de grande relevância na degradação de recursos hídricos (BUZELLI; CUNHA-SANTINHO, 2013).

Ademais, territórios urbanos e rurais, por intermédio do descarte incorreto de dejetos e substâncias, contribuem com impactos nos sistemas hídricos. Ambas podem colaborar com descargas de substâncias orgânicas e inorgânicas (algumas tóxicas), seja diretamente no corpo hídrico, por escoamento ou infiltração de fontes de poluição, 
como produtos utilizados para produção e limpeza. Esses lançamentos indevidos podem provocar danos à fauna aquática e doenças na população, ademais, a problemática pode ser intensificada por degradação ambiental, como a retirada da mata ciliar (BELLUTA et al., 2016; SCORSAFAVA et al., 2010).

Em relação aos rios urbanos, em que as correntes de água têm o percurso em áreas urbanas, a alteração da qualidade das águas representa um risco ao progresso sustentável nesses locais, principalmente em nações em desenvolvimento, como o Brasil. Isto porque a relação dos problemas de qualidade nos corpos hídricos com o descarte de resíduos domésticos ou mesmo industriais nestes, ainda brutos, ou seja, sem tratamento adequado, ocasiona um acréscimo negativo de substâncias orgânicas e inorgânicas ao rio (ISLAM et al., 2015; CHEN, 2017).

Nesse contexto, a problemática do descarte inadequado de materiais orgânicos secos e úmidos, e os impactos causados por estes, no ambiente, tem como questão principal o destino apropriado dos remanescentes destes. Em virtude disso, foi instituída a Política Nacional de Resíduos Sólidos (PNRS), Lei n. 12.305: 2010, Decreto n. 7.404:2010, que dispõe sobre o destino correto de resíduos, a fim de mitigar a quantidade produzida por geradores e os impactos ambientais. Para tanto, é necessário um fortalecimento dos princípios da gestão sustentável de resíduos, por parte de geradores e do município, com o intuito de cumprir com as políticas estabelecidas (JACOBI; BESEN, 2011).

Consequentemente, no Brasil, é indubitável a poluição hídrica, tal fato associa-se a má administração executada no país, mesmo havendo recursos públicos investidos para evitar este quadro crítico, além da falta de rigorosidade no cumprimento das políticas das águas, necessitando de um efetivo ciclo Plan, Do, Check, Act (PDCA ${ }^{[5]}$, em inglês), para auxiliar a política pública, através da determinação das ações, execução, acompanhamento e correção do plano em um todo, para melhor gestão, e consequente conservação da qualidade dos recursos hídricos, especialmente no que diz respeito ao descarte indevido de resíduos(GONTIJO JÚNIOR, 2013). 
Em relação a legislação sobre a qualidade da água, no Brasil, tem-se a Resolução CONAMA n.357 (BRASIL, 2005), a água do rio Tocantins é classificada como do tipo doce classe 2, em que as águas podem ser destinadas:

a) ao abastecimento para consumo humano, após tratamento convencional;

b) à proteção das comunidades aquáticas;

c) à recreação de contato primário, tais como natação, esqui aquático e mergulho, conforme Resolução CONAMA n. 274 (BRASIL, 2000);

d) à irrigação de hortaliças, plantas frutíferas e de parques, jardins, campos de esporte e lazer, com os quais o público possa vir a ter contato direto; e

e) à aquicultura e à atividade de pesca (BRASIL, 2005, p. 4).

Na mesma Resolução, no art. 15, os padrões de águas doces de categoria 2 são os mesmos aplicáveis à ordem 1, exceto:

II - Coliformes termotolerantes: para uso de recreação de contato primário deverá ser obedecida a Resolução CONAMA n. 274(BRASIL, 2000). Para os demais usos, não deverá ser excedido um limite de 1.000 coliformes termotolerantes por 100 mililitros em $80 \%$ ou mais de pelo menos seis amostras coletadas durante o período de um ano, com frequência bimestral. A E. coli poderá ser determinada em substituição aos parâmetros coliformes termotolerantes de acordo com limites estabelecidos pelo órgão ambiental competente;

IV - Turbidez: até 100 UNT;

$\mathrm{V}-\mathrm{DBO}_{5}$ a $20^{\circ} \mathrm{C}$ até5 $\mathrm{mg} / \mathrm{L} \mathrm{O}$ 
VI - OD, em qualquer amostra, não inferior a $5 \mathrm{mg} / \mathrm{L} \mathrm{O}$ (BRASIL, 2005, p. 10).

Outros padrões como, por exemplo, fósforo total $\left(P_{\text {total }}\right)$ para ambiente lótico, nitrogênio total ( $\mathrm{N}_{\text {total }}$ e potencial Hidrogeniônico $(\mathrm{pH})$, também constam nesta Resolução (Tabela 1).

Tabela 1- Limites de padrões de qualidade de águas doces, Classe 2. CONAMA.

\begin{tabular}{|c|c|c|c|}
\hline Parâmetros & Mínimo & Máximo & Condição \\
\hline $\mathrm{DBO}_{5} 20^{\circ} \mathrm{C}$ & & $5 \mathrm{mg} / \mathrm{L}$ & \\
\hline Nitrato $\left(\mathrm{NO}^{-3}\right)$ & & $\begin{array}{l}10,0 \\
\mathrm{mg} / \mathrm{L}\end{array}$ & \\
\hline Nitrito $\left(\mathrm{NO}^{-2}\right)$ & & $\begin{array}{l}1,0 \\
\mathrm{mg} / \mathrm{L}\end{array}$ & \\
\hline \multirow[t]{4}{*}{ Nitrogênio amoniacal total } & & $\begin{array}{l}3,7 \\
\mathrm{mg} / \mathrm{L}\end{array}$ & $\mathrm{pH} \leq 7,5$ \\
\hline & & $2,0 \mathrm{mg} / \mathrm{L}$ & $\begin{array}{l}7,5<\mathrm{pH} \\
\leq 8,0\end{array}$ \\
\hline & & $\begin{array}{l}1,0 \\
\mathrm{mg} / \mathrm{L}\end{array}$ & $\begin{array}{l}8,0<\mathrm{pH} \\
\leq 8,5\end{array}$ \\
\hline & & $\begin{array}{l}0,5 \\
\mathrm{mg} / \mathrm{L}\end{array}$ & $\mathrm{pH}>8,5$ \\
\hline $\begin{array}{l}\text { Fósforo total (ambiente } \\
\text { lótico e tributários de } \\
\text { ambientes intermediários) }\end{array}$ & & $\begin{array}{l}0,1 \\
\mathrm{mg} / \mathrm{L}\end{array}$ & \\
\hline Oxigênio Dissolvido (OD) & $5 \mathrm{mg} / \mathrm{L}$ & & \\
\hline pH & 6,0 & 9,0 & \\
\hline Turbidez & & $\begin{array}{l}100 \\
\text { UNT }\end{array}$ & \\
\hline
\end{tabular}

Fonte: BRASIL (2005).

Legendas: DBO: Demanda Bioquímica de Oxigênio. pH.: potencial Hidrogeniônico. NTU: Unidades Nefelométricas de Turbidez

No art. 14, inciso I, dessa Resolução, são determinados que os materiais sobrenadantes, como espumas não naturais, óleos e graxas, substâncias que interfiram no paladar ou olfato, corantes de procedência antrópica e resíduos sólidos

Disponível em: https://www.nucleodoconhecimento.com.br/engenharia-ambiental/influencia-deresiduos 
objetáveis devem estar imperceptíveis, ou seja, não devem possuir propriedades organolépticas.

Já sobre a Resolução CONAMA n. 274 (BRASIL, 2000), citada no art. 15, inciso II, Resolução CONAMA n. 357 (BRASIL, 2005), que trata sobre os critérios de balneabilidade, classifica a condição das águas doces, salobras e salinas em categorias própria e imprópria. No art. $2^{\circ}, \S 1^{\circ}$ da Resolução 274 , as águas próprias são classificadas assim por meio de resultados da contagem de coliformes, e classificam-se em:

a) Excelente: quando em $80 \%$ ou mais de um conjunto de amostras obtidas em cada uma das cinco semanas anteriores, colhidas no mesmo local, houver, no máximo, 250 coliformes fecais (termotolerantes) ou 200 Escherichia coli ou 25 Enterococcus por 100 mililitros;

b) Muito Boa: quando em $80 \%$ ou mais de um conjunto de amostras obtidas em cada uma das cinco semanas anteriores, colhidas no mesmo local, houver, no máximo, 500 coliformes fecais (termotolerantes) ou 400 Escherichia coli ou 50 Enterococcus por 100 mililitros;

c) Satisfatória: quando em $80 \%$ ou mais de um conjunto de amostras obtidas em cada uma das cinco semanas anteriores, colhidas no mesmo local, houver, no máximo 1.000 coliformes fecais (termotolerantes) ou 800 Escherichia coli ou 100 Enterococcus por 100 mililitros (BRASIL, 2000, p. 257).

Quanto as impróprias, além de não atenderem aos padrões para águas próprias, são avaliadas de outras formas $\left(\S 4^{\circ}\right)$ :

b) valor obtido na última amostragem for superior a 2500 coliformes fecais (termotolerantes) ou 2000 Escherichia coli ou 400 Enterococcus por 100 mililitros; 
c) incidência elevada ou anormal, na região, de enfermidades transmissíveis por via hídrica, indicada pelas autoridades sanitárias;

d) presença de resíduos ou despejos, sólidos ou líquidos, inclusive esgotos sanitários, óleos, graxas e outras substâncias, capazes de oferecer riscos à saúde ou tornar desagradável a recreação;

e) 6,0 <pH > 9,0 (águas doces), à exceção das condições naturais;

f) floração de algas ou outros organismos, até que se comprove que não oferecem riscos à saúde humana;

g) outros fatores que contraindiquem, temporária ou permanentemente, o exercício da recreação de contato primário (BRASIL, 2000, p. 257).

Dessa forma, a poluição aquática por efluentes domésticos, em razão da deficiência de saneamento básico, é fato nos 143 municípios paraenses, por isso, justifica-se esta pesquisa, e esses fatos incrementam a relevância da mesma, cujo objetivo é caracterizar a água do rio Tocantins, Marabá - PA, quanto aos parâmetros hídricos físicos, químicos e microbiológicos, em dois pontos sob a influência do lançamento de resíduos, no período seco e chuvoso, e relacionar os dados obtidos com os padrões e normas legais.

\section{MATERIAL E MÉTODOS}

Os materiais utilizados para mensurações dos parâmetros ambientais como, temperatura e potencial Hidrogeniônico $(\mathrm{pH})$ foram cedidos pela Universidade do Estado do Pará- UEPA (Tabela 2). 
Tabela 2- Instrumentos utilizados para a mensuração das variáveis ambientais. Marabá - PA.

\begin{tabular}{|c|c|c|c|}
\hline Instrumentos & Marca & Modelo & Finalidade \\
\hline Termômetro & Instrutherm & $\begin{array}{l}\text { Tipo } \\
\text { espeto }\end{array}$ & $\begin{array}{l}\text { Mensurar a temperatura in situ da } \\
\text { água }\end{array}$ \\
\hline pHmêtro & Produto OEM ${ }^{*}$ & & $\begin{array}{l}\text { Mensurar o potencial } \\
\text { Hidrogeniônico in situ da água }\end{array}$ \\
\hline Turbidímetro & MS Tecnopon & $\begin{array}{l}\text { TB } \\
1000 \mathrm{P}\end{array}$ & $\begin{array}{l}\text { Mensurar a turbidez ex situ da } \\
\text { água }\end{array}$ \\
\hline Balança & KNWaagen & $\begin{array}{l}\mathrm{KN} \\
320 / 3\end{array}$ & Pesar frascos e meios de cultura \\
\hline Autoclave vertical & Prismatec & CS & $\begin{array}{l}\text { Esterilizar os meios de cultura } \\
\text { para a análise microbiológica }\end{array}$ \\
\hline $\begin{array}{l}\text { Estufa } \\
\text { bacteriológica }\end{array}$ & $\begin{array}{l}\text { Ethik } \\
\text { Technology }\end{array}$ & 403-3D & $\begin{array}{l}\text { Incubar os meios de cultura com } \\
\text { as amostras para analisar } \\
\text { coliformes totais }\end{array}$ \\
\hline Banho-Maria & Hemoquimica & $\begin{array}{l}\mathrm{HM} \\
1003\end{array}$ & $\begin{array}{l}\text { Incubar os meios de cultura com } \\
\text { as amostras para analisar } \\
\text { coliformes termotolerantes }\end{array}$ \\
\hline $\begin{array}{l}\text { Agitador magnético } \\
\text { com aquecimento }\end{array}$ & Quimis & Q261-22 & $\begin{array}{l}\text { Evaporar a água das amostras } \\
\text { para a análise de resíduo total }\end{array}$ \\
\hline $\begin{array}{l}\text { Estufa para } \\
\text { secagem }\end{array}$ & DeLeo & $\begin{array}{l}\mathrm{A} 2 \mathrm{C} \\
0208\end{array}$ & Secar o resíduo total \\
\hline
\end{tabular}

${ }^{*}$ Original Equipment Manufacturer - Fabricante de Equipamento Original.

Fonte: autores (2018).

O método empregado foi o dedutivo, sintetizado por Matias-Pereira (2016), pois, o crescimento populacional ocorrido na cidade em análise, bem como a estagnação da extensão do saneamento básico, prejudica a qualidade dos corpos hídricos. A 
pesquisa teve abrangência quantitativa e qualitativa, com natureza aplicada e procedimento exploratório, descritos por Sakamoto e Silveira (2014).

Esse método foi associado ao levantamento documental com recorte temporal compreendido entre 2010 e 2018, para obtenção de dados secundários mais recentes em links eletrônicos de acesso livre, Scientific Eletronic Library Online (SciELO), Comissão de Aperfeiçoamento do Pessoal do Nível Superior (CAPES), Ministério do Meio Ambiente (MMA), Ministério da Cidade, Prefeitura Municipal de Marabá e Secretaria Municipal de Vigilância Sanitária de Marabá.

\subsection{FISIOGRAFIA DO MUNICÍPIO}

A pesquisa foi realizada na cidade de Marabá, localizada na mesorregião do Sudeste Paraense (Figura 1), e representada com o auxílio de OSGeo (2016), com sede identificada nas coordenadas geográficas $05^{\circ} 21^{\prime} 54^{\prime \prime}$ Latitude Sul e $04^{\circ} 07^{\prime} 24^{\prime \prime}$ Longitude WGr. 
Figura 1- a) Mapa Político de localização do Pará; b) Mapa físico de localização de Marabá; c) Vista superior da área objeto dessa pesquisa: Orla Marítima de Marabá PA.
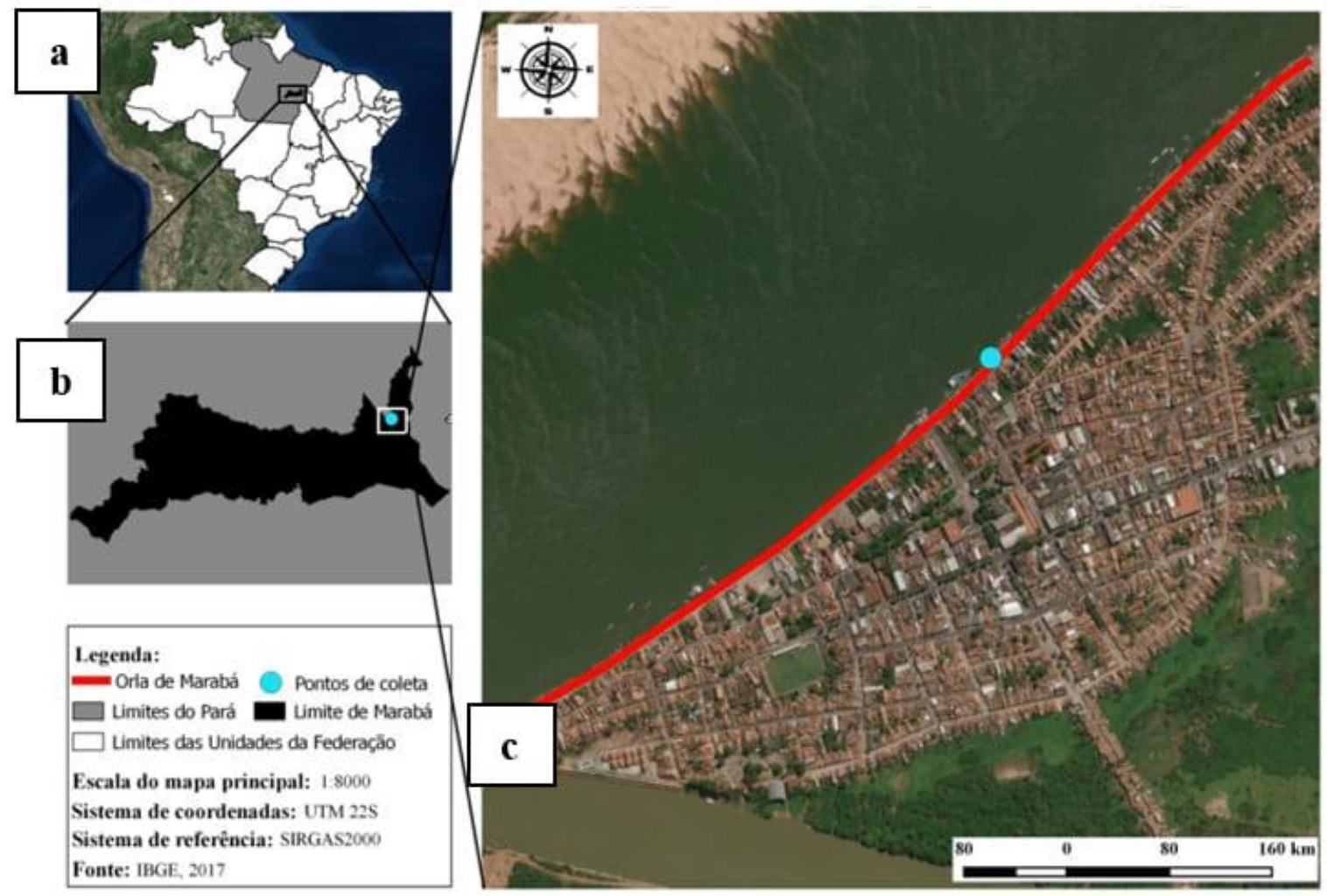

Fonte: autores (2018).

Em Marabá, os parâmetros ambientais (precipitação, temperatura e umidade relativa do ar), apresentam, anualmente, tendências de variações para mais ou para menos (Tabela 3).

Disponível em: https://www.nucleodoconhecimento.com.br/engenharia-ambiental/influencia-deresiduos 
Tabela 3 - Valores para as médias nas três décadas climáticas analisadas. MarabáPA.

\begin{tabular}{|c|c|c|c|c|c|}
\hline \multicolumn{6}{|c|}{ Estação Marabá - OMM: 82562} \\
\hline $\begin{array}{l}\text { Décadas } \\
\text { analisad }\end{array}$ & $\begin{array}{c}\text { PPR total } \\
(\mathrm{mm})\end{array}$ & $\begin{array}{c}\text { Tmáxima } \\
\left({ }^{\circ} \mathrm{C}\right)\end{array}$ & $\begin{array}{c}\mathbf{T}_{\text {compensada }} \\
{ }^{\left({ }^{\circ} \mathrm{C}\right)}\end{array}$ & $\mathbf{T}$ minima $\left({ }^{\circ} \mathrm{C}\right)$ & UR $(\%)$ \\
\hline as & $\bar{X}$ & $\overline{\bar{X}}$ & $\bar{X}$ & $\bar{X}$ & $\bar{X}$ \\
\hline $\begin{array}{c}1988- \\
1997\end{array}$ & 162,47 & 32,44 & 27,01 & 22,96 & 81,09 \\
\hline $\begin{array}{l}1998- \\
2007\end{array}$ & 144,97 & 33,14 & 27,67 & 23,69 & 73,87 \\
\hline $\begin{array}{c}2008- \\
2017\end{array}$ & 153,17 & 33,16 & 27,7 & 23,37 & 74,51 \\
\hline
\end{tabular}

Fonte: INMET (2018).

Legendas: PPR: precipitação. T: temperatura. UR: umidade relativa do ar.

O intervalo de dezembro a maio representa o período chuvoso e, de junho a novembro o período seco, e a temperatura média anual é de $26,5^{\circ} \mathrm{C}$, (máxima $\pm 31,0^{\circ} \mathrm{C}$; mínima = de $22,0^{\circ} \mathrm{C}$ ). $\mathrm{O}$ município possui o índice pluviométrico de cerca de $2.000 \mathrm{~mm} / \mathrm{ano}$, com alta umidade relativa do ar (FAPESPA, 2016).

\subsection{DAS AMOSTRAGENS}

A amostragem correspondeu a oito coletas de água, realizadas no intervalo de dezembro de 2017 a setembro de 2018 (quatro no período chuvoso; quatro no seco), no contra fluxo do rio, conforme o recomendado pela Fundação Nacional de Saúde (FUNASA, 2013) e o Guia Nacional de Coleta e Preservação de Amostras (BRANDÃO et al., 2011), na margem esquerda do Rio Tocantins, Orla de Marabá - PA,perímetro compreendido entre a Av. Marechal Deodoro, Rua Santa Terezinha e Travessa Mestre Olívio, em dois pontos distintos: $\mathrm{P}_{1}$, delatitude $5,346618^{\circ} \mathrm{S}$ e longitude $49,135026^{\circ} \mathrm{W}$; e $\mathrm{P}_{2}$, de latitude $5,346257^{\circ} \mathrm{S}$ e longitude $49,134636^{\circ} \mathrm{W}$ (Figura 2). 
Figura 2- Posições planialtimétricas dos pontos de coleta $\mathrm{P}_{1}$ e $\mathrm{P}_{2}$. Marabá -PA.

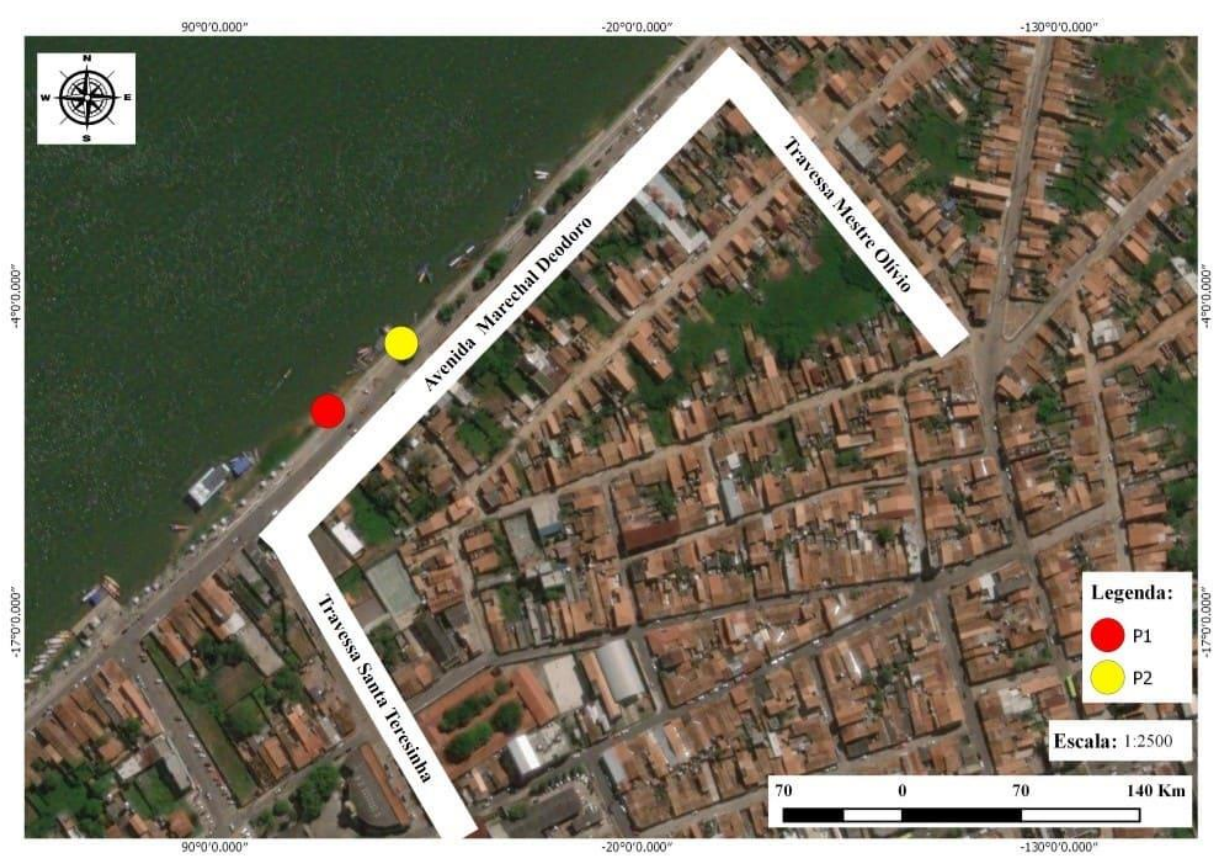

Fonte: autores (2018).

Posteriormente, as amostras foram conduzidas para análises laboratoriais, de acordo com o preconizado pelo Manual Prático de Análise de Águas (FUNASA, 2013). Tais análises ocorreram no laboratório VetPlus Agribusiness Solutions e foram complementadas nos Laboratórios de aulas práticas (Química; Engenharia Ambiental e Florestal) do Campus VIII, Marabá - PA (Tabela 4).

Tabela 4- Especificações do local em que foram feitas as análises laboratoriais, tipo e método empregado. Marabá - PA.

\begin{tabular}{|c|c|c|c|c|}
\hline Laboratório & $\begin{array}{ll}\text { Tipo de } \\
\text { Análise }\end{array}$ & $\begin{array}{l}\text { Análise } \\
\text { Laboratorial }\end{array}$ & $\begin{array}{l}\text { Método } \\
\text { utilizado }\end{array}$ & $\begin{array}{l}\text { Ano de } \\
\text { publicação }\end{array}$ \\
\hline $\begin{array}{l}\text { VetPlus } \\
\text { Agribusiness } \\
\text { Solutions }\end{array}$ & Química & $\begin{array}{l}\mathrm{DBO}^{2} ; \quad \mathrm{NT}^{3} ; \\
\mathrm{PT}^{4}\end{array}$ & SMWW $^{6}$ & 2012 \\
\hline
\end{tabular}

Disponível em: https://www.nucleodoconhecimento.com.br/engenharia-ambiental/influencia-deresiduos 


\begin{tabular}{|l|l|l|l|l|}
\hline Química - UEPA & Química & OD $^{5}$ & $\begin{array}{l}\text { Winkler } \\
\text { modificado }\end{array}$ & S.D \\
\hline $\begin{array}{l}\text { Engenharia } \\
\begin{array}{l}\text { Florestal } \\
\text { Ambiental - UEPA }\end{array}\end{array}$ & Física & Resíduo total & $\begin{array}{l}\text { NTI 013 - } \\
\text { SABESP7 }\end{array}$ & 1999 \\
\hline $\begin{array}{l}\text { Engenharia } \\
\text { Ambiental - UEPA }\end{array}$ & Microbiológica & Coliformes & FUNASA & 2013 \\
\hline
\end{tabular}

'Soluções de agronegócio; ${ }^{2}$ Demanda Bioquímica de Oxigênio; ${ }^{3}$ Nitrogênio Total; ${ }^{4}$ Fósforo Total; ${ }^{5}$ Oxigênio Dissolvido; ${ }^{6}$ Standard Methods for the Examination of Water and Wastewater; ${ }^{7}$ Norma Técnica Interna da Companhia de Saneamento Básico do Estado de São Paulo.

Fonte: autores (2018).

\subsection{TRATAMENTO ESTATÍSTICO DOS DADOS}

Quanto ao tratamento estatístico dos dados obtidos empregou-se a Estatística Descritiva, por contada presença de dados quantitativos, contínuos e intervalares, com o uso: da média, do desvio padrão (para que se observe a dispersão das observações efetuadas sobre os parâmetros ambientais em relação aos valores intermediários) e do coeficiente de variação (a fim de averiguar a homogeneidade do conjunto amostral obtido), além da Correlação de Pearson, cujas grandezas para $r$ foram adaptados a partir das utilizadas por Porto, Jesus e Pereira Junior (2017), com padrões positivos e negativos (Tabela 5).

Tabela 5-Valores utilizados para $r$.

\begin{tabular}{|l|l|l|}
\hline Valores & Caracterização & Relação \\
\hline 0 & Não há & Não há \\
\hline 0,10 a 0,30 & Correlação fraca & Direta \\
\hline$-0,10$ a $-0,30$ & Correlação fraca & Inversa \\
\hline
\end{tabular}

Disponível em: https://www.nucleodoconhecimento.com.br/engenharia-ambiental/influencia-deresiduos 


\begin{tabular}{|l|l|l|}
\hline 0,40 a 0,60 & Correlação média & Direta \\
\hline$-0,40$ a -0,60 & Correlação média & Inversa \\
\hline 0,70 a 1,00 & Correlação forte & Direta \\
\hline$-0,70$ a $-1,00$ & Correlação forte & Inversa \\
\hline
\end{tabular}

Fonte: adaptado a partir dos dados contidos em Porto, Jesus e Pereira Júnior (2017).

Fez-se uso de planilhas eletrônicas contidas no software Excel (MICROSOFT CORPORATION, 2016) no programa computacional BioEstat 5.3 (AYRES et al., 2007).

\section{RESULTADOS E DISCUSSÃO}

\subsection{PARÂMETROS HÍDRICOS FÍSICOS}

A análise dos dados obtidos para o $\mathrm{pH}$ indicou que, em ambos os períodos, os valores obtidos em $\mathrm{P}_{1}$ e $\mathrm{P}_{2}$ enquadram-se nos padrões estabelecidos $(6,0 \leq \mathrm{pH} \leq 9,0)$ na Resolução n. 357 (BRASIL, 2005).

Tabela 5- Valores médios para pH (média, desvio padrão, coeficiente de variação) obtidos para P1 e P2, período chuvoso e seco. Marabá - PA.

\begin{tabular}{|c|c|c|c|c|}
\hline \multicolumn{5}{|c|}{$\mathbf{P}_{\mathbf{1}}$} \\
\hline & $\overline{\mathbf{x}}$ & & $\boldsymbol{\sigma}$ & $\mathbf{C V}(\mathbf{\%})$ \\
\hline $\mathbf{P C}$ & 7.39 & $\mathbf{\pm}$ & 0.10 & 1.35 \\
\hline $\mathbf{P S}$ & 7.23 & \pm & 0.28 & 3.87 \\
\hline & \multicolumn{3}{|c|}{$\mathbf{P}_{\mathbf{2}}$} \\
\hline & $\overline{\mathbf{x}}$ & & $\boldsymbol{\sigma}$ & $\mathbf{C V}(\mathbf{\%})$ \\
\hline PC & 7.23 & \pm & 0.24 & 3.31 \\
\hline PS & 7.10 & $\mathbf{\pm}$ & 0.08 & 1.12 \\
\hline
\end{tabular}

Fonte: autores (2018) 
Legendas: pH.: Potencial hidrogeniônico; PC: Período chuvoso. PS: Período seco; ${ }^{\bar{x}}$ :Média o: Desvio padrão. CV (\%): Coeficiente de variação.

A análise dos dados estatísticos permite afirmar que os valores obtidos para $0 \mathrm{pH}$ estão bastante homogêneos, devido à média encontrada para o desvio padrão $(0,08<\sigma>0,28)$ condensar-se em torno da média $(7,23)$.

No estudo efetuado por Siqueira, Aprile e Miguéis (2012), em Parauapebas - PA, região sudeste do estado, concluíram que, para $0 \mathrm{pH}$, há uma tendência de elevação/diminuição para os valores desse parâmetro que se aproxima da neutralidade. Isso pode ser justificado pela presença de sedimentos e altos índices de matéria orgânica presentes naturalmente no local, e, indica também que é comum a obtenção de valores baixos na região amazônica. Os dados obtidos nesta pesquisa indicam uma tendência à neutralidade, com variações ligeiramente ácidas, que corroboram com o estudo em Parauapebas.

Ainda que o rio Tocantins tenha nascente no estado de Goiás, na serra Dourada, entre os municípios de Ouro Verde de Goiás e Petrolina de Goiás, tem a foz no Pará, e, atravessa o município de Marabá. Neste caso, as características geológicas, como a predominância do solo Podzólico Vermelho-Amarelo, e climáticas, como a temperatura média anual dos municípios (Marabá $=26,5 \stackrel{\circ}{ } \mathrm{C}$; Parauapebas $=26,35$ $\left.{ }^{\circ} \mathrm{C}\right)$, são semelhantes, o que explica a similaridade dos valores obtidos.

Como em Marabá foi comprovado o lançamento de efluentes à margem de onde se efetuaram as coletas, a tendência a neutralidade pode ser justificada pela oferta nutricional estável, ou seja, as taxas de matéria orgânica oriundas dos despejos de efluentes juntamente aos sedimentos em suspensão de origem natural não apresentaram grandes alterações durante o período da pesquisa, o que confere um $\mathrm{pH}$ com tendendo a neutralidade, o que revela similaridade com a pesquisa realizada em Parauapebas. 
Para a interrelação entre parâmetros hídricos, os dados obtidos indicaram que o pH sofre interferências da temperatura da água, especialmente no período chuvoso ( $\mathrm{P}_{1}$, $\left.r=0,43 ; P_{2}, r=-0,86\right)$, onde ela se torna levemente ácida. Já no período seco, a tendência é para alcalinidade $\left(P_{1}, r=-0,14 ; P_{2}, r=-0,65\right)$. Nesse caso, verifica-se que estes parâmetros são, no corpo hídrico, grandezas inversamente proporcionais porque a temperatura, no período seco, eleva-se e a deposição de MO, carreada pela chuva, no corpo hídrico diminui, o que pode ser comprovado pela concentração do $\mathrm{OD}(9,38<\mathrm{OD}>11,2 \mathrm{mg} / \mathrm{L})$, em P1 e $\mathrm{P}_{2}$, respectivamente (Figura 3).

Figura 3 - Correlação entre temperatura e pH no período seco em P1 e P2.

Pl

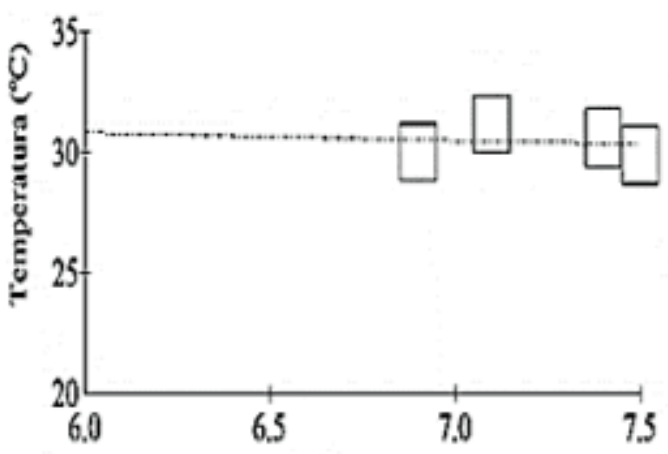

pH
P2

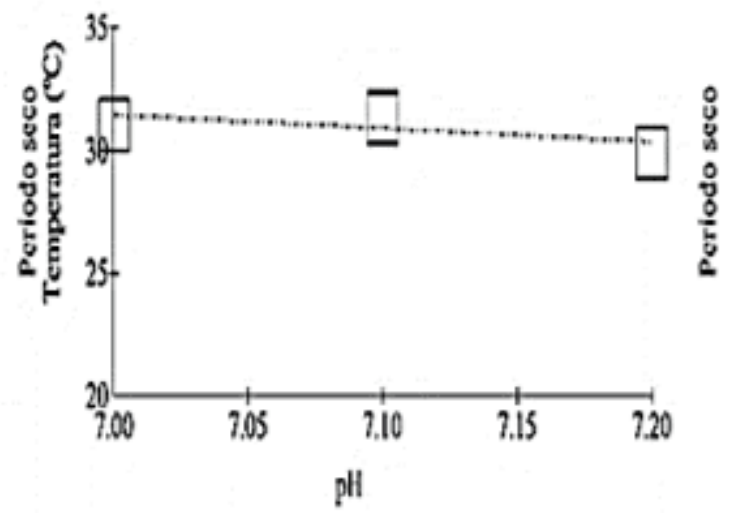

Fonte: autores (2018)

Em relação aos valores de temperatura mensurados não se notou diferença considerável entre os pontos $\mathrm{P}_{1}$ e $\mathrm{P}_{2}$ no período chuvoso e no período seco (Tabela $6)$. 
Tabela 6 - Valores médios para temperatura (média, desvio padrão, coeficiente de variação) obtidos para $P_{1}$ e $P_{2}$, período chuvoso e seco. Marabá - PA.

\begin{tabular}{|c|c|c|c|c|c|}
\hline \multicolumn{5}{|c|}{$\mathrm{P}_{1}$} \\
\hline & $\overline{\mathbf{X}}$ & & $\boldsymbol{\sigma}$ & $\mathbf{C V}(\%)$ \\
\hline PC & 30.48 & \pm & 1.37 & 4.49 \\
\hline PS & 30.43 & \pm & 0.60 & 1.97 \\
\hline & \multicolumn{3}{|c|}{$\mathrm{P}_{2}$} \\
\hline & $\overline{\mathbf{X}}$ & & $\boldsymbol{\sigma}$ & $\mathbf{C V}(\%)$ \\
\hline PC & 30.43 & \pm & 1.40 & 4.60 \\
\hline PS & 30.9 & \pm & 0.69 & 2.23 \\
\hline
\end{tabular}

Fonte: autores (2018)

Legendas: $\mathrm{pH}$.: Potencial hidrogeniônico. PC: Período chuvoso. PS: Período seco. $\sigma$ : Desvio padrão. CV (\%): Coeficiente de variação.

A análise dos dados estatísticos permite afirmar que os valores obtidos para temperatura estão um pouco variados, devido as médias encontradas para o desvio padrão $(0,6<\sigma>1,4)$, com números mais distribuídos em torno da média $(30,56)$.

A tendência ao equilíbrio nos dois períodos analisados, é dependente, internamente, das variações sazonais e diurnas, além da estratificação vertical. Externamente, a latitude, altitude, estações do ano, períodos do dia, taxas de fluxo e profundidade. Outro fator, é ao despejo de efluentes. Nesse caso, os pontos analisados recebem efluentes por meio de anilhas. Porém, esse despejo não foi suficiente para provocar elevação da temperatura.

Na pesquisa realizada na llha do Marajó, por Alves et al. (2012), foi indicado que, valores entre $27^{\circ} \mathrm{C}$ e $\cong 31^{\circ} \mathrm{C}$ podem ser justificados pelas características naturais das águas amazônicas, onde as tendências de variação da temperatura ocorrem de acordo com as variações dos parâmetros atmosféricos, logo, as menores temperaturas estão relacionadas ao aumento da cobertura de nuvens, que diminui a incidência solar no rio, enquanto as maiores quando há maior incidência solar. 
Estas alterações ocorrem não de um período sazonal a outro, mas sim em pequenas variações ao longo do ano. Isto foi constatado também nesta pesquisa, haja vista que não houve diferença de temperatura considerável nos dois pontos em ambos os períodos, o que corrobora com a pesquisa realizada na llha do Marajó.

Nota-se também que as médias e o desvio padrão não apresentaram discrepância nos dois pontos, independente das estações, indicando que as tendências de elevação ou diminuição da temperatura independem dos períodos sazonais, o que corrobora com a pesquisa na llha do Marajó.

A Turbidez tem como limite estabelecido até 100 Unidades Nefelométricas de Turbidez (UNT) pela Resolução n. 357 Os valores obtidos nesta pesquisa variaram significativamente ao longo dos períodos e de acordo com os pontos (Tabela 7) (BRASIL, 2005).

Tabela 7- Valores médios para turbidez (média, desvio padrão, coeficiente de variação) obtidos para $P_{1}$ e $P_{2}$, período chuvoso e seco. Marabá - PA.

\begin{tabular}{|c|c|c|c|c|}
\hline \multicolumn{5}{|c|}{$\mathrm{P}_{1}$} \\
\hline & $\overline{\mathbf{x}}$ & & $\boldsymbol{\sigma}$ & $\mathbf{C V}(\%)$ \\
\hline PC & 30.83 & \pm & 9.90 & 32.11 \\
\hline PS & 31.25 & \pm & 32.53 & 104.09 \\
\hline & \multicolumn{3}{|c|}{$\mathrm{P}_{2}$} \\
\hline & $\overline{\mathbf{X}}$ & & $\boldsymbol{\sigma}$ & $\mathbf{C V}(\%)$ \\
\hline PC & 24.85 & \pm & 12.50 & 50.30 \\
\hline PS & 37.6 & \pm & 38.60 & 102.65 \\
\hline
\end{tabular}

Fonte: autores (2018).

Legendas: PC: Período chuvoso. PS: Período seco. ${ }^{\bar{x}}$ : Média. $\sigma:$ Desvio padrão. CV (\%): Coeficiente de variação. 
A análise dos dados estatísticos permite afirmar que os valores obtidos para turbidez estão bastante variados, bem como o alto desvio padrão $(9,9<\sigma>38,6)$, que está bem distribuído em torno da média $(31,13)$.

Os dados obtidos e analisados nos dois pontos de amostragem dessa pesquisa, em $\mathrm{P}_{1}$, a tendência foi de diminuição (8 NTU), com distribuição homogênea das partículas ( $\sigma=32.51 \mathrm{NTU} ; x=31,25 \mathrm{NTU}$ ), e de elevação em P2 (95 NTU). Isso pode estar relacionado com tanto no período chuvoso, quanto no seco, indicaram que há uma tendência de baixo espalhamento das partículas que interferem na turbidez (Ex.: sólidos em suspensão, detritos orgânicos, etc.). Em ambos os pontos analisados, há presença de anilhas de esgotos sanitários, no entanto, sua presença não interfere na turbidez.

No período pluvial, os dados analisados de $\mathrm{P}_{1}$ e $\mathrm{P}_{2}$ foram baixos e mais homogêneos, todavia na estiagem, foram mais dispersos, com máximas em junho e agosto, respectivamente, portanto, todos estão dentro do permitido. Embora a média dos pontos não tenha se alterado drasticamente, o coeficiente de variação mostra que os dados possuem divergências ao longo da realização da pesquisa, indicando que os níveis de turbidez variaram não só junto aos meses do ano, como também de uma coleta a outra, especialmente nos meses de estiagem. Tais dados inesperados podem ser explicados pelas interferências antrópicas.

Buzelli e Cunha-Santino (2013), em estudo efetuado em Barra Bonita - SP, concluíram que, apesar do índice de turbidez aumentar no período chuvoso naturalmente devido ao carreamento de sedimentos na água, o despejo de esgoto contribui para o aumento de partículas suspensas e consequente elevação da turbidez, em ambos os períodos. Em Marabá, a análise dos dados obtidos indicou que há uma similaridade entre esta pesquisa e aquela realizada em Barra Bonita.

A análise dos dados de obtidos do parâmetro resíduo total indicou que, houve tendência a variações nas concentrações dos resíduos, as quais foram calculadas apenas para o valor íntegro, não havendo fracionamento dos resíduos (Tabela 8). 
Tabela 8 - Valores médios para Resíduo Total (média, desvio padrão, coeficiente de variação) obtidos para $P_{1}$ e $P_{2}$, período chuvoso e seco. Marabá - PA.

\begin{tabular}{|c|c|c|c|c|}
\hline \multicolumn{2}{|c|}{} & \multicolumn{2}{c|}{$\mathrm{P}_{1}$} \\
\hline & $\overline{\mathbf{x}}$ & & $\boldsymbol{\sigma}$ & $\mathbf{C V}(\%)$ \\
\hline PC & 325.00 & \pm & 378.59 & 116.48 \\
\hline PS & 325.00 & \pm & 206.16 & 63.43 \\
\hline & \multicolumn{3}{|c|}{$\mathrm{P}_{2}$} \\
\hline & $\overline{\mathbf{X}}$ & & $\boldsymbol{\sigma}$ & $\mathbf{C V}(\%)$ \\
\hline PC & 250.00 & \pm & 4767.60 & 186.96 \\
\hline PS & 250.00 & \pm & 238.05 & 95.22 \\
\hline
\end{tabular}

Fonte: autores (2018).

Legendas: PC: Período chuvoso. PS: Período seco. ${ }^{\bar{x}}$ : Média. $\sigma$ : Desvio padrão. CV (\%): Coeficiente de variação.

O coeficiente de variação dos dados indica que estes se divergem tanto em comparação aos períodos como em relação aos pontos. No entanto, as médias se mantêm nos pontos quando se compara o período chuvoso ao seco.

Em ambos os pontos, os valores analisados podem estar relacionados à presença de despejo de efluentes não tratados, resíduos e atividades de pesca no local, como visto na pesquisa realizada por Silva e Araújo (2017), em São Paulo - SP, e que foi observado nesta pesquisa próximo aos locais de coleta, fator determinante nos dados deste parâmetro do longo dos períodos.

\subsection{PARÂMETROS HÍDRICOS QUÍMICOS}

Os dados obtidos para DBO indicaram que as concentrações, tanto em $\mathrm{P}_{1}$ quanto em $\mathrm{P}_{2}$, em média, foram superiores, em duas a cinco vezes mais quando comparado com o valor de referências permitido: $5 \mathrm{mg} / \mathrm{L}$ (Tabela 9). 
Tabela 9- Valores médios para DBO (média, desvio padrão, coeficiente de variação) obtidos para $\mathrm{P}_{1}$ e $\mathrm{P}_{2}$, período chuvoso e seco. Marabá - PA.

\begin{tabular}{|c|c|c|c|c|c|}
\hline \multicolumn{5}{|c|}{$\mathrm{P}_{1}$} \\
\hline & $\overline{\mathbf{X}}$ & & $\boldsymbol{\sigma}$ & $\mathbf{C V}(\%)$ \\
\hline PC & 5.90 & \pm & 4.43 & 75.08 \\
\hline PS & 4.95 & \pm & 3.10 & 62.62 \\
\hline & \multicolumn{3}{|c|}{$\mathrm{P}_{2}$} \\
\hline & $\overline{\mathbf{X}}$ & & $\boldsymbol{\sigma}$ & $\mathbf{C V}(\%)$ \\
\hline PC & 6.80 & \pm & 6.35 & 93.38 \\
\hline PS & 4.35 & \pm & 2.06 & 47.35 \\
\hline
\end{tabular}

Fonte: autores (2018).

Legendas: DBO: Demanda Bioquímica de Oxigênio. PC: Período chuvoso. PS: Período seco. : Média. o: Desvio padrão. CV (\%): Coeficiente de variação.

A análise dos dados obtidos indicou maiores concentrações de $\mathrm{DBO}$, em $\mathrm{P}_{2}$, período chuvoso, nesse caso, pode ter ocorrido menor entrada de matéria orgânica, por escoamento superficial, ou via anilha de efluentes, como isso não houve depleção do DBO, ou ainda, a mineralização ocorreu de forma lenta, pois, na estiada, houve, nesse mesmo ponto, uma redução $(4,35 \mathrm{mg} / \mathrm{L})$, abaixo do valor de referência (BRASIL, 2005).

Tal indicação se justifica pelo fato de que, no período pluvial, a temperatura da água tem tendência a equilíbrio, ou seja, não sofre elevação, logo, não há perda expressiva do gás oxigênio $\left(\mathrm{O}_{2}\right)$ para a atmosfera, como acontece no período seco. Notou-se que as concentrações de DBO obtidas nos meses de dezembro, janeiro e junho em ambos os pontos estão acima do limite (5mg/L) preconizado pela Resolução n. 357 , bem como a do mês de setembro em $\mathrm{P}_{1}$ (BRASIL, 2005).

Em Rio Branco - AC, Santi et al. (2012) realizaram uma pesquisa sobre os valores de DBO em rios, e os dados tratados se justificam pela alta presença do esgotamento sanitário na área, e considera-se também, sob o ponto de vista geológico da região

Disponível em: https://www.nucleodoconhecimento.com.br/engenharia-ambiental/influencia-deresiduos 
amazônica, a presença de matéria orgânica oriunda de processos naturais. Estes fatos também foram verificados em Marabá - PA, pois, também se observou grande concentração principalmente no período chuvoso em $\mathrm{P}_{1}$ conforme é justificado pelo valor de Pearson para DBO e fósforo total de 0,6787 o qual é caracterizado como correlação direta (Figura 4).

Figura 4 - Correlação de Pearson de DBO e fósforo total no período chuvoso em P1.

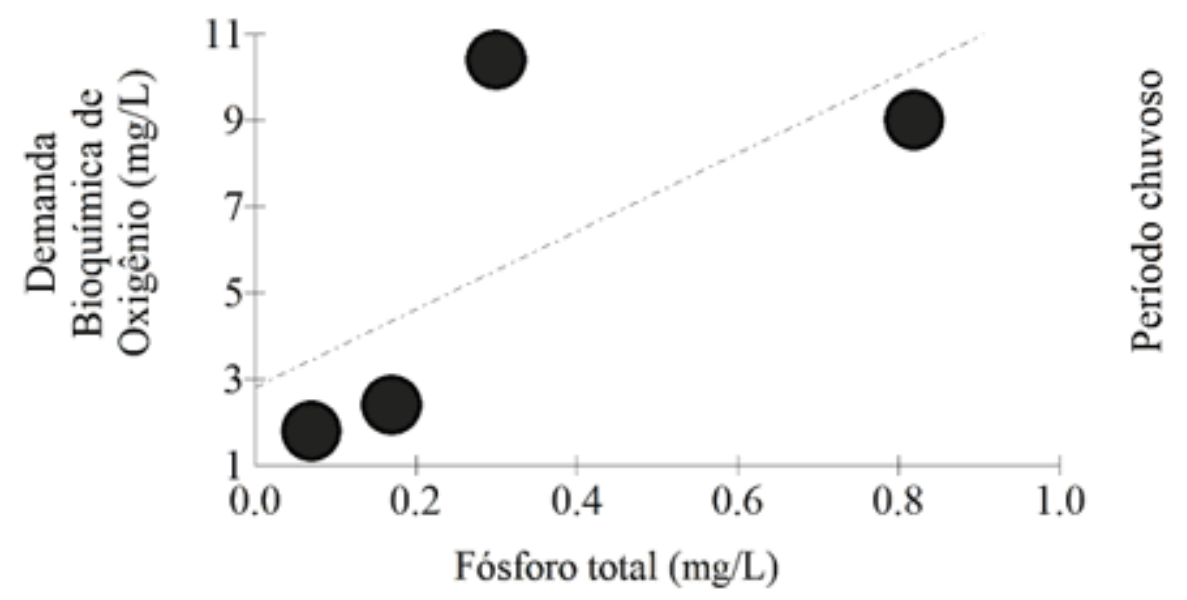

Fonte: autores (2018).

Nos meses de fevereiro, março, julho e agosto, em ambos os pontos, e no mês de setembro em $\mathrm{P}_{2}$, as concentrações de DBO estão de acordo com os padrões estabelecidos pela Resolução n. 357, o que pode se relacionar à vazão média do rio Tocantins antes da época de estiagem e a tendência de elevação da temperatura (BRASIL, 2005).

No período seco, os dados indicaram que tanto em $\mathrm{P}_{1}$, quanto em $\mathrm{P}_{2}$, houve tendência de diminuição nas concentrações de $\mathrm{DBO}(1,20<\mathrm{DBO}>5 \mathrm{mg} / \mathrm{L})$. Esses valores estão em não conformidade com o preconizado com Resolução CONAMA 357 (BRASIL, 2005), que estabelece valor igual a $5 \mathrm{mg} / \mathrm{L}$.

As taxas menores de DBO podem estar relacionadas à presença de descarte de resíduos gerados nos estabelecimentos e residências, na água, além de atividades

Disponível em: https://www.nucleodoconhecimento.com.br/engenharia-ambiental/influencia-deresiduos 
de pesca de peixes em $\mathrm{P}_{1}$ (Figura $5 \mathrm{a}$ ), assim como lançamento de esgoto sem tratamento, que também pode ser visto nas proximidades de $\mathrm{P}_{2}$ (Figura $5 \mathrm{~b}$ ).

Figura 5 - A) Presença de atividades de pesca próximas ao $\mathrm{P}_{1}$; B) Despejo de efluentes próximo ao ponto de coleta $\mathrm{P}_{2}$.

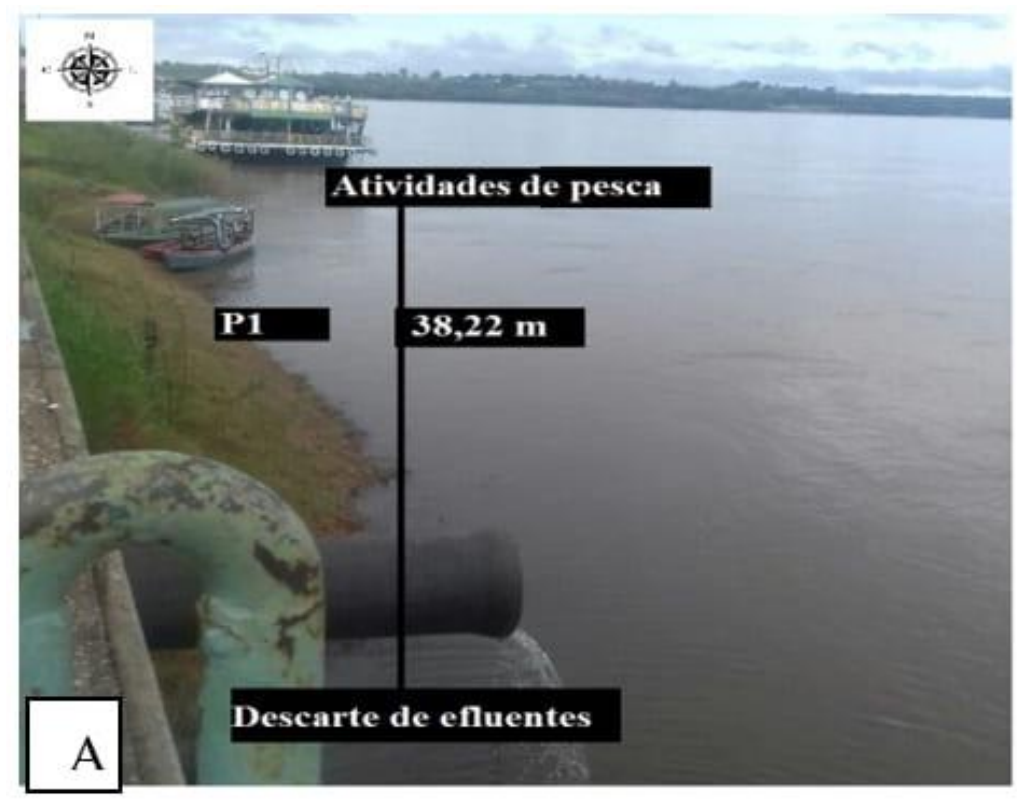

Fonte: autores (2018).

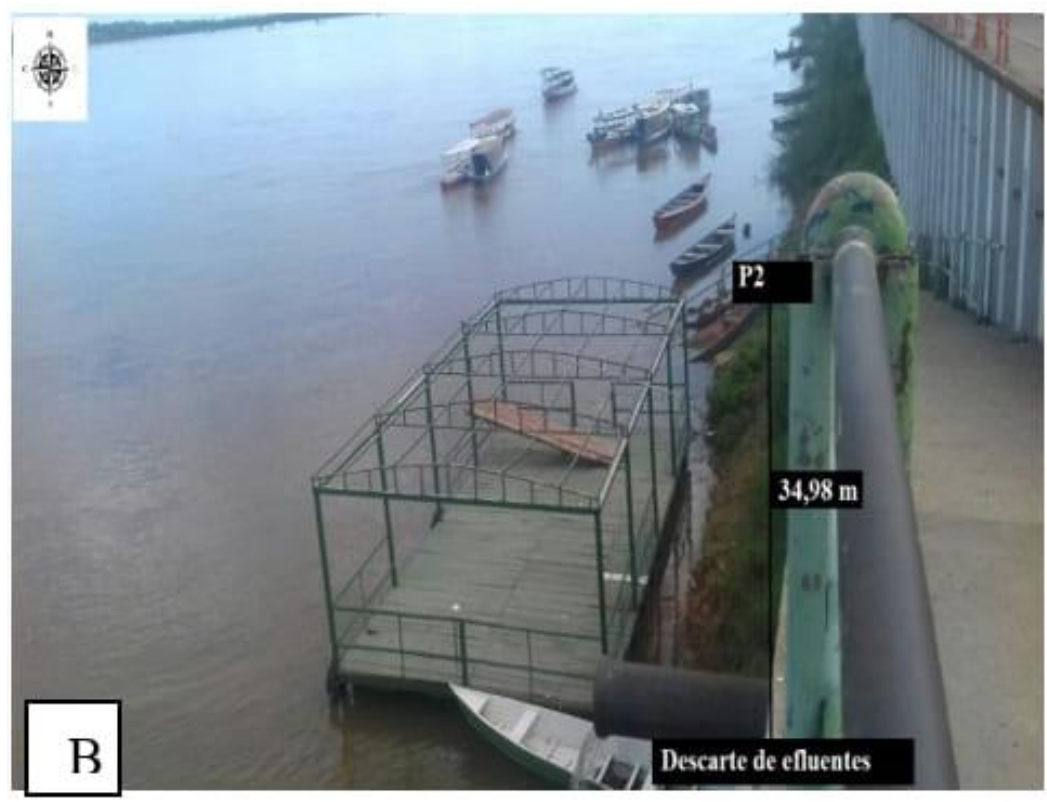

Fonte: autores (2018).

RC: 32914

Disponível em: https://www.nucleodoconhecimento.com.br/engenharia-ambiental/influencia-deresiduos 
Em Bragança - PA, no rio Caeté (GORAYEB; LOMBARDO; PEREIRA, 2010), e no rio Araguari (BÁRBARA et al., 2010), esse último perpassa por três municípios: Porto Grande, Ferreira e Cutias - PR, foram efetuados estudos acerca das concentrações do DBO em período seco. Os autores concluíram que estas estão interligadas a tendência de elevação da temperatura na água, bem como da velocidade da vazão no período anual. No rio Tocantins, os dados destes parâmetros podem justificar as diferenças de concentrações devido à influência destas variáveis, pelo fato das coletas de amostras terem sido realizadas em dois períodos sazonais: chuvoso e seco.

Em relação às concentrações de Nitrogênio total, nos dois pontos e período, os dados obtidos indicaram apenas uma concentração em desacordo com o preconizado (3,7 $\mathrm{mg} / \mathrm{L}$ para $\mathrm{pH} \leq 7,5$ ) na Resolução $\mathrm{n}$. 357 , e foi em $\mathrm{P}_{1}$, no mês de setembro(Tabela 10) (BRASIL, 2005).

Tabela 10 - Valores médios para Nitrogênio Total (média, desvio padrão, coeficiente de variação) obtidos para P1 e P2, período chuvoso e seco. Marabá - PA.

\begin{tabular}{|c|c|c|c|c|}
\hline \multicolumn{5}{|c|}{$\mathrm{P}_{1}$} \\
\hline & $\overline{\mathbf{x}}$ & & $\boldsymbol{\sigma}$ & $\mathbf{C V}(\%)$ \\
\hline PC & 1.18 & \pm & 0.63 & 53.38 \\
\hline PS & 3.55 & \pm & 5.70 & 160.05 \\
\hline \multicolumn{4}{|c|}{$\mathrm{P}_{2}$} \\
\hline & $\overline{\mathbf{x}}$ & $\boldsymbol{\sigma}$ & $\mathbf{C V}(\%)$ \\
\hline PC & 1.18 & \pm & 0.66 & 55.93 \\
\hline PS & 0.65 & \pm & 0.30 & 46.15 \\
\hline
\end{tabular}

Fonte: autores (2018).

Legendas: NTotal: Nitrogênio total. PC: Período chuvoso. PS: Período seco. ${ }^{\overline{\mathrm{x}}}$ : Média. б: Desvio padrão. CV (\%): Coeficiente de variação.

Estudo efetuado por Santi et al. (2012), em Rio Branco - AC, concluiu que, valores similares são justificados devido aos processos de decomposição da matéria orgânica, liberando compostos nitrogenados. Os dados obtidos nas coletas do Rio 
Tocantins, inclusive o acima dos padrões, podem estar relacionados à presença do ponto de emissão de efluentes domésticos sem tratamento prévio próximo aos pontos, que é notado visivelmente na superfície da água (Figura 6), em discordância com o art. 14, inciso I da Resolução do CONAMA referida anteriormente.

Figura 6 - Espumas oriundas do efluente despejado próximo aos pontos P1 e P2, Marabá - PA.

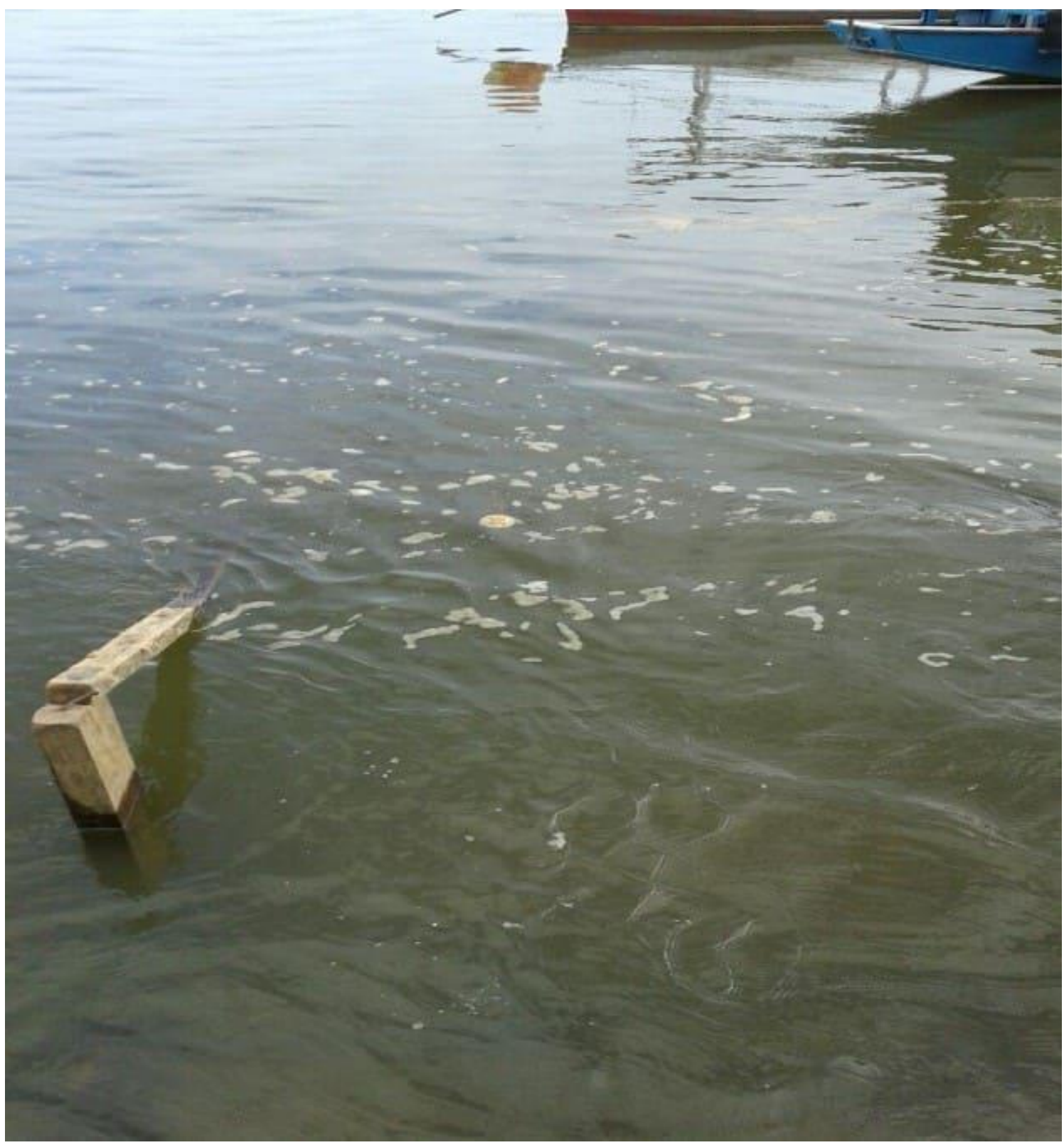

Fonte: autores (2018)

RC: 32914

Disponível em: https://www.nucleodoconhecimento.com.br/engenharia-ambiental/influencia-deresiduos 
Em conformidade com o demonstrado na figura 4,os valores obtidos na correlação de Pearson também destacam o excesso de carga orgânica no rio devido à relação crescente de nitrogênio e fósforo, os quais, no período chuvoso foram 0,5988 em $\mathrm{P}_{1}$ e 0,7739 em $P_{2}$, parâmetros diretamente relacionados, enquanto que no período seco nos dois pontos de coleta, "r" foi maior que 0,70 (P1=0,856; P2=0,8642), caracterizando a correlação entre estas variáveis como forte, direta e positiva (Figura 7).

Figura 7 - Gráficos da correlação de Pearson de nitrogênio total e fósforo total dos pontos de coleto (P1 e P2) no período chuvoso e seco.

P1

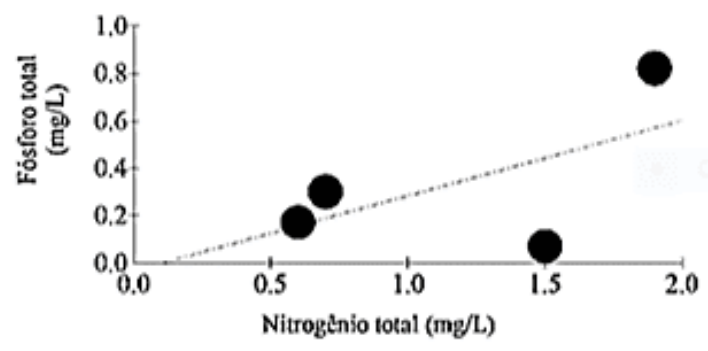

Pl

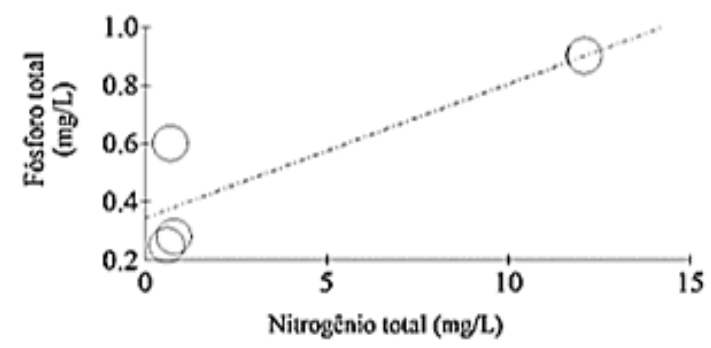

P2

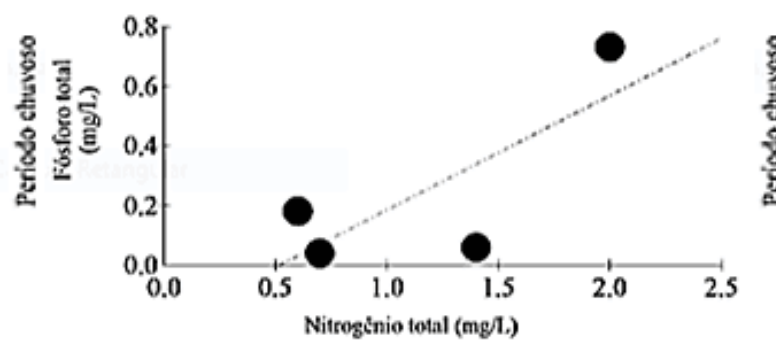

P2

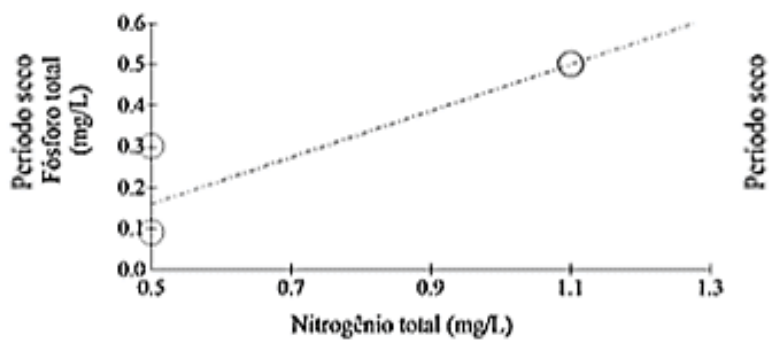

Fonte: autores (2018)

Os valores permitidos para o Fósforo total equivalem a $0,1 \mathrm{mg} / \mathrm{L}$, todavia, os dados da pesquisa em Marabá mostraram tendências a elevação em $P_{1}$ e $P_{2}$ (Tabela 11). 
Tabela 11- Valores médios para Fósforo Total (média, desvio padrão, coeficiente de variação) obtidos para $P_{1}$ e $P_{2}$, período chuvoso e seco. Marabá - PA.

\begin{tabular}{|c|c|c|c|c|}
\hline \multicolumn{5}{|c|}{$\mathrm{P}_{1}$} \\
\hline & $\overline{\mathbf{x}}$ & & $\boldsymbol{\sigma}$ & $\mathbf{C V}(\%)$ \\
\hline PC & 0.34 & \pm & 0.33 & 97.05 \\
\hline PS & 0.51 & \pm & 0.31 & 60.78 \\
\hline & \multicolumn{3}{|c|}{$\mathrm{P}_{2}$} \\
\hline & $\overline{\mathbf{x}}$ & & $\boldsymbol{\sigma}$ & $\mathbf{C V}(\%)$ \\
\hline PC & 0.25 & \pm & 0.32 & 128.00 \\
\hline PS & 0.13 & \pm & 0.11 & 84.61 \\
\hline
\end{tabular}

Fonte: autores (2018)

Legendas: PTotal: Fósforo total. PC: Período chuvoso. PS: Período seco. $\quad \overline{\mathrm{x}}$ : Média. б: Desvio padrão. CV (\%): Coeficiente de variação.

A pesquisa realizada por Ríos -Villamizar, Martins Júnior e Waichman (2011) nos municípios de Boca do Acre e Beruri - AC, indicou uma relação à valores semelhantes e a proximidade ao início e término do período chuvoso, onde a maior carga detrítica, de erosões e carreamento de sedimentos é transportada nas águas, além da presença de matéria orgânica. Os valores máximos obtidos em Marabá também se assemelham a estes períodos, corroborando com a pesquisa realizada no Acre.

Os dados de Oxigênio Dissolvido no período chuvoso foram elevados em $\mathrm{P}_{1}$ e $\mathrm{P}_{2}$, enquanto no período seco houve uma queda (Tabela 12). 
Tabela 12- Valores médios para Oxigênio Dissolvido (média, desvio padrão, coeficiente de variação) obtidos para $\mathrm{P}_{1}$ e $\mathrm{P}_{2}$, período chuvoso e seco. Marabá - PA.

\begin{tabular}{|c|c|c|c|c|}
\hline \multicolumn{5}{|c|}{$\mathrm{P}_{1}$} \\
\hline & $\overline{\mathbf{X}}$ & & $\boldsymbol{\sigma}$ & $\mathbf{C V}(\%)$ \\
\hline PC & 11.2 & \pm & 5.76 & 51.42 \\
\hline PS & 6.15 & \pm & 4.10 & 66.66 \\
\hline & \multicolumn{3}{|c|}{$\mathrm{P}_{2}$} \\
\hline & $\overline{\mathbf{x}}$ & & $\boldsymbol{\sigma}$ & $\mathbf{C V}(\%)$ \\
\hline PC & 9.38 & \pm & 4.00 & 42.64 \\
\hline PS & 6.35 & \pm & 1.92 & 30.23 \\
\hline
\end{tabular}

Fonte: autores (2018)

Legendas: OD: Oxigênio Dissolvido. PC: Período chuvoso. PS: Período seco.

$\overline{\mathrm{x}}$ : Média. б: Desvio padrão. CV (\%): Coeficiente de variação.

Os dados, quando comparados à Resolução CONAMA n. 357:2005, foi inferior ao permitido ( $5 \mathrm{mg} / \mathrm{L})$, verificado em $\mathrm{P}_{1}$, nos meses de março, junho, julho e setembro, ambos com concentração de $4,1 \mathrm{mg} / \mathrm{L}$. No estudo efetuado por Oliveira e Cunha (2014), em Laranjal do Jari - AP, concluiu que, a elevada temperatura diminui a solubilidade de oxigênio na água devido à alta incidência solar.

\subsection{QUANTO A ANÁLISE MICROBIOLÓGICA}

A análise dos dados obtidos para coliformes totais indicou que, tanto em $\mathrm{P}_{1}$ quanto em $\mathrm{P}_{2}$, há ocorrência, em ambos os períodos de coleta, e isso é prejudicial tanto a qualidade da água, quanto da balneabilidade do Rio Tocantins, pois, à frente do local onde se realizou a pesquisa, tem-se um alúvio que a população da área denomina de "praia do Tucunaré", muito frequentada pelos banhistas durante o verão amazônico.

As médias do Número Mais Provável (NMP) dos coliformes totais, tanto na estação chuvosa quanto seca, em ambos os pontos, ultrapassou 1.000/100 ml (Tabela 13).

Disponível em: https://www.nucleodoconhecimento.com.br/engenharia-ambiental/influencia-deresiduos 
Tabela 13- Valores médios para Coliformes Totais (média, desvio padrão, coeficiente de variação) obtidos para P1 e P2, período chuvoso e seco. Marabá - PA

\begin{tabular}{|c|c|c|c|c|}
\hline \multicolumn{5}{|c|}{$\mathrm{P}_{1}$} \\
\hline & $\overline{\mathbf{X}}$ & & $\boldsymbol{\sigma}$ & $\mathbf{C V}(\mathbf{\%})$ \\
\hline PC & 1600 & \pm & 0 & 0 \\
\hline PS & 1600 & \pm & 0 & 0 \\
\hline & \multicolumn{3}{|c|}{$\mathrm{P}_{2}$} \\
\hline & $\overline{\mathbf{X}}$ & & $\boldsymbol{\sigma}$ & $\mathbf{C V}(\%)$ \\
\hline PC & 1425 & \pm & 350 & 24.56 \\
\hline PS & 1600 & \pm & 0 & 0 \\
\hline
\end{tabular}

Fonte: autores (2018).

Legendas: ColTotal: Coliformes totais. PC: Período chuvoso. PS: Período seco.

$\overline{\mathrm{x}}$ : Média. .: Desvio padrão. CV (\%): Coeficiente de variação.

Os dados obtidos indicaram um único mês em que o NMP foi inferior a 1600, em março, em $\mathrm{P}_{2}$. Esses altos valores podem ser justificados pelo despejo direto de esgoto que ocorre na Orla de Marabá. Na pesquisa efetuada por Martins et al. (2017), nos municípios de João Pessoa e Cabedelo - PB, na praia de Cabo Branco, indicaram a influência do esgoto na qualidade da água, que foi considerada imprópria para balneabilidade. Entretanto, no mês de agosto, em $\mathrm{P}_{2}$, a determinação do NMP foi prejudicada, pois, a combinação de tubos positivos obtida (5-0-5) não consta na tabela do manual da FUNASA (2013).

As médias do Número Mais Provável (NMP) dos coliformes termotolerantes, tanto na estação chuvosa quanto seca, em ambos os pontos, também ultrapassou 1.000/100 $\mathrm{ml}$ (Tabela 14). 
Tabela 14- Valores médios para Coliformes Termotolerantes (média, desvio padrão, coeficiente de variação) obtidos para $\mathrm{P}_{1}$ e $\mathrm{P}_{2}$, período chuvoso e seco. Marabá - PA.

\begin{tabular}{|c|c|c|c|c|}
\hline \multicolumn{5}{|c|}{$\mathrm{P}_{1}$} \\
\hline & $\overline{\mathbf{X}}$ & & $\boldsymbol{\sigma}$ & $\mathbf{C V}(\%)$ \\
\hline PC & 1366.667 & $\mathbf{1}$ & 404.1452 & 29.5716 \\
\hline PS & 1600 & \pm & 0 & 0 \\
\hline & \multicolumn{4}{|c|}{$\mathrm{P}_{2}$} \\
\hline & $\overline{\mathbf{X}}$ & & $\boldsymbol{\sigma}$ & $\mathbf{C V}(\%)$ \\
\hline PC & 1425 & \pm & 350 & 24.5614 \\
\hline PS & 1287.5 & \pm & 625 & 48.54369 \\
\hline
\end{tabular}

Fonte: autores (2018).

Legendas: ColTermo: Coliformes termotolerantes. PC: Período chuvoso. PS: Período seco. $^{\bar{x}}$ : Média. $\sigma:$ Desvio padrão. CV (\%): Coeficiente de variação.

Em relação a este parâmetro, os dados indicaram dois meses em que o NMP foi inferior a 1600, em fevereiro, em $\mathrm{P}_{1}$, e em março e julho, em $\mathrm{P}_{2}$. Ademais, houve a indeterminação do NMP pelas combinações de tubos positivos obtidas em dezembro (4-5-4) e setembro (0-5-3), em $\mathrm{P}_{1}$, visto que também não constam na tabela do manual da FUNASA (2013).

\section{CONCLUSÃO}

A caracterização da água do rio Tocantins, Marabá - PA, no período chuvoso e seco, no trecho analisado, o qual é influenciado pelo lançamento de resíduos, indicou quanto aos parâmetros hidrológicos físicos hídricos, cumprimento do estabelecido para águas doces Classe 2, de acordo com a classificação da Resolução CONAMA n. 357 (BRASIL, 2005). Entretanto, para a mesma classe de águas, a caracterização quanto aos parâmetros hidrológicos químicos hídricos, indicou desacordo com esta Resolução.

Para os padrões de balneabilidade, conforme a Resolução n. 274 (BRASIL, 2000), a água do rio Tocantins é considerada imprópria para a recreação de contato primário,

Disponível em: https://www.nucleodoconhecimento.com.br/engenharia-ambiental/influencia-deresiduos 
pois, há o despejo de sólidos e líquidos, contendo substâncias como óleos e graxas que são passíveis de causar riscos à saúde ou comprometer o lazer da população.

\section{REFERÊNCIAS}

ALVES, I. C. C.et al. Qualidade das águas superficiais e avaliação do estado trófico do Rio Arari (Ilha de Marajó, norte do Brasil). Acta Amazônica, v. 42, n. 1, p.115-124, jan./dez. 2012.

AYRES, M. et al. BioEstat 5.3: aplicações estatísticas nas áreas das ciências biológicas e médicas. Belém: MCT; IDSM; CNPq, 2007. 364 p.

BÁRBARA, V. F. et al. Monitoramento sazonal da qualidade da água do rio Araguari/AP. Revista Biociências, Taubaté, v. 16, n. 1, p. 57-72, jul./dez. 2010.

BELLUTA, I. et al. Qualidade da Água, Carga Orgânica e de Nutrientes na Foz do Córrego da Cascata: Contribuição da Sub-Bacia para a Represa de Barra Bonita, Rio Tietê (SP). Revista Brasileira de Geografia Física, v. 09, n. 01, p. 305-318, jan./fev.2016.

BUZELLI, G. M.; CUNHA-SANTINO, M. B. Análise e diagnóstico da qualidade da água e estado trófico do reservatório de Barra Bonita, SP. Ambiente e Água - An Interdisciplinary Journal of Applied Science, Taubaté, v.8, n.1,p.186-205, abr.2013.

BRANDÃO, C. J. et al. (Org.). Guia Nacional de Coletas e Preservação de amostras: água, sedimentos, comunidades aquáticas e efluentes líquidas. Brasília: ANA-CETESB. Agência Nacional de Águas - Companhia de Saneamento do Estado de São Paulo, 2011.

BRASIL. Resolução n. 274, de 29 de novembro de 2000, do Conselho Nacional do Meio Ambiente - CONAMA. Revogada pela Resolução n. 357:2005. Define os critérios de balneabilidade em águas brasileiras. Diário Oficial [da] República Federativa do Brasil.n.18, de 25 de janeiro de 2001, Seção 1, páginas 70-71. 
Disponível em: <http://www.mma.gov.br/port/conama/legiabre.cfm?codlegi=272>. Acesso em: 06 fev. 2018.

BRASIL. Resolução n. 357, de 17 de março de 2005, do Conselho Nacional do Meio Ambiente - CONAMA. Alterada pela Resolução 410:2009 e pela 430:2011. Dispõe sobre a classificação dos corpos de água e diretrizes ambientais para o seu enquadramento, bem como estabelece as condições e padrões de lançamento de efluentes, e dá outras providências. Diário Oficial [da] República Federativa do Brasil. n. 053, de 18 de março de 2005, páginas. 58-63. Disponível em: <http://www.mma.gov.br/port/conama/res/res05/res35705.pdf>. Acesso em: 05 fev. 2018.

CHEN, W. Y. Environmental externalities of urban river pollution and restoration: a hedonic analysis in Guangzhou (China). Landscape and Urban Planning, v. 157, p. 170-179, 2017.

FAPESPA. FUNDAÇÃO AMAZÔNIA DE AMPARO A ESTUDOS E PESQUISAS. Estatísticas Municipais Paraenses: Marabá. Diretoria de Estatística e de Tecnologia e Gestão da Informação. Belém, n. 1, jul./dez. 2016. 60 f.

FUNASA.FUNDAÇÃO NACIONAL DE SAÚDE. Manual prático de análise de água. 4. ed. Brasília: Funasa, 2013. 150 p.

GONTIJO JÚNIOR, W. C. Uma avaliação da política brasileira de recursos hídricos baseada em dez casos de estudo. 2013. 330 f. Tese (Doutorado em Tecnologia Ambiental e Recursos Hídricos). Universidade de Brasília, Faculdade de Tecnologia, Programa de Pós-Graduação em Tecnologia ambiental e Recursos Hídricos. Brasília, 2013.

GORAYEB, A.; LOMBARDO, M. A.; PEREIRA, L. C. C. Qualidade da água e abastecimento na Amazônia: o exemplo da bacia hidrográfica do rio Caeté. Mercator - Revista de Geografia da UFC, Fortaleza. v. 9, n. 18, p. 135-157, jan./abr. 2010. 
IBGE - Instituto Brasileiro de Geografia e Estatística. Mapas. Bases e Referenciais. 2017.

<ttp://geoftp.ibge.gov.br/organizacao_do_territorio/malhas_territoriais/malhas_munici pais/municipio_2015/Brasil/BR/>. Acesso em: 01 jun. 2018.

INMET -Instituto Nacional de Meteorologia. Banco de Dados Meteorológicos para Ensino P Pesquisa. 2018Disponível em: $<$ http://www.inmet.gov.br/portal/index.php?r=bdmep/bdmep >. Acesso em: 25 fev. 2018.

ISLAM, M. S. et al. Heavy metal pollution in surface water and sediment: apreliminaryassessment of an urban river in a developing country. Ecological Indicators, v. 48, p. 282-291, 2015.

JACOBI, P. R.; BESEN, G. R. Gestão de resíduos sólidos em São Paulo: desafios da sustentabilidade. Estudos Avançados, São Paulo, v. 25, n. 71, p. 135-158, abr. 2011.

MARTINS, L. M. M. et al. Análise dos parâmetros de Balneabilidade: um estudo de caso sobre as praias dos municípios de João Pessoa e Cabedelo/PB. Revista InterScientia, João Pessoa, v. 5, n. 1, p. 116-128, abr. 2017.

MATIAS-PEREIRA, J. Manual de metodologia da pesquisa científica. 4. ed. São Paulo: Atlas, 2016.

MICROSOFT CORPORATION. Inc. Excel. Versão 1811. Software, 2016.

OLIVEIRA, B. S. S.; CUNHA, A. C. Correlação entre qualidade da água e variabilidade da precipitação no sul do Estado do Amapá. Revista Ambiente e Água, Taubaté, v. 9, n. 2, p. 261-275, abr./jun.2014.

OSGEO - Open Source Geoespatial Foundation. Inc. QGis. Versão 2.18. Software, 2016. 
PORTO, M. L.; JESUS, E. S.; PEREIRA JUNOR, A. Análise das tendências nas relações entre fluxo de veículos, arborização e os níveis de intensidade de ruído. Ecologia e Nutrição Florestal, Santa Maria, v.5, n.3, p.87-97, set./dez. 2017.

RÍOS-VILLAMIZAR, E. A.; MARTINS JÚNIOR, A. F.; WAICHMAN, A. V. Caracterização físico-química das águas e desmatamento na Bacia do rio Purus, Amazônia Brasileira Ocidental. Revista Geográfica Acadêmica, Goiânia, v.5, n.2, p. 54-65, jul./dez. 2011.

SAKAMOTO, C. K.; SILVEIRA, I. O. Como fazer projetos de iniciação científica. São Paulo: Paulus, 2014.

SANTI, G. M. et al. Variabilidade espacial de parâmetros e indicadores de qualidade da água na sub-bacia hidrográfica do igarapé São Francisco, Rio Branco, Acre, Brasil. Ecología Aplicada, Lima, v. 11 n. 1, p. 23-31, jan./ago. 2012.

SCORSAFAVA, M. A. et al. Avaliação físico-química da qualidade de água de poços e minas destinada ao consumo humano. Revista do Instituto Adolfo Lutz, São Paulo, v. 69, n. 2, p. 229-232, abr./jun. 2010.

SILVA, M. A.; ARAÚJO, R. R. Análise temporal da qualidade da água no córrego limoeiro e no Rio Pirapozinho no estado de São Paulo - Brasil. Revista FORMAÇÃo (ONLINE), São Paulo, v. 1, n.24, p. 182-203, jan. /abr. 2017.

SIQUEIRA, G. W.; APRILE, F.; MIGUÉIS, A. M. Diagnóstico da qualidade da água do rio Parauapebas (Pará - Brasil). Acta Amazonica, Manaus, v. 42, n. 3, p. 413-422, jul. /set. 2012.

5.Planejar, agir, checar e corrigir.

Enviado: Fevereiro, 2019.

Aprovado: Junho, 2019. 